\title{
ESTUDO DA QUALIDADE AMBIENTAL DA BACIA HIDROGRÁFICA DO CÓRREGO DO RANCHO EM ADAMANTINA - SP
}

\author{
José Aparecido dos Santos ${ }^{1}$ \\ Alan Lima dos Reis ${ }^{2}$ \\ Willian Endo Borim ${ }^{3}$
}

\begin{abstract}
RESUMO
De forma preocupante, os problemas socioambientais se manifestam no meio urbano e rural com certa intensidade, no qual, algumas literaturas citam estes agravantes se relacionando às atividades antrópicas, como exemplo: (erosões, assoreamentos, desmatamentos, urbanização em áreas de riscos, contaminação de águas superficiais e subterrâneas). Considerou-se em aproveitar os aspectos naturais, ou seja, o alto curso da bacia hidrográfica do córrego do rancho em Adamantina SP, para realizar estudos referentes ao uso e ocupação do solo, refletindo sua qualidade ambiental. Para o processamento das imagens foram utilizados os softwares AUTO CAD, SPRING e GOOGLE EARTH, estes processando as imagens datadas de 1962, 1971, 2002 e 2013. Os resultados apontam para uma mudança acentuada na expansão urbana, saúde pública e modificação de culturas. Um trabalho deste gênero assume patamar significativo, pois, oferece uma base de dados para eventuais aprimoramentos relacionados à bacia hidrográfica em foco.

PALAVRAS CHAVES: Bacia Hidrográfica. Geoprocessamento. Qualidade Ambiental.

\section{ENVIRONMENTAL QUALITY STUDY OF BASIN RANCH STREAM IN ADAMANTINA - SP}

\begin{abstract}
In an alarming way, the social environmental problems are manifested in urban and rural areas with certain intensity, in this way, some books mention these circumstances related with human activities, such as erosion, silting, deforestation, urbanization in dangerous areas, contamination of surface and underground water, and other aspects. It was considered to make use of natural aspects, in other words, the upper reaches of a watershed situated in a stream in Adamantina - SP, to conduct studies about the use and occupation of the soil, considering its environmental quality. To analyze the images it was used the following software's AUTO CAD, SPRING and GOOGLE EARTH; these softwares processed the images that are dated in 1962, 1971, 2002 and 2013. The results point to a marked change of the urban sprawl, the public health system and the agricultural crops. This kind of project takes on a significant level, once it offers a data base to possible improvement related to the watershed in focus.

KEYWORDS: Watershed. Geoprocessing. Environmental Quality.

\footnotetext{
${ }^{1}$ Doutor em Geografia pela UNICAMP, Professor efetivo da FAI, e-mail: cido@fai.com.br

${ }^{2}$ Graduando em Engenharia Ambiental pelas Faculdades Adamantinenses Integradas - FAl, e-mail: al.reis2012@hotmail.com

${ }_{3}$ Graduando em Agronomia pelas Faculdades Adamantinenses Integradas, e-mail: williantecnicoagropecuaria@hotmail.com
} 


\title{
ESTUDIO DE CALIDAD AMBIENTAL DE LA CUENCA DEL RANCHO SECUENCIA EN ADAMANTINA - SP
}

\begin{abstract}
RESUMO
Alarmantemente, los problemas sociales y ambientales viene manifestando en las zonas rurales y urbanas con una cierta intensidad, en el que algunos de la literatura citada estos agravantes están relacionados con las actividades humanas por ejemplo: (erosiones, colmatación, deforestación, urbanización en áreas peligrosas, la contaminación de las aguas superficiales y subterráneas). Se consideró en el aprovechamiento de los aspectos naturales así, la parte alta de las cuencas hidrográficas del arroyo del rancho en Adamantina - SP, para realizar estudios sobre el uso y la ocupación del suelo, lo que refleja su calidad ambiental. Para el procesamiento de imágenes se utilizaron el software AUTO CAD, SPRING e GOOGLE EARTH, estos haciendo el procesamiento de las imágenes fechadas de 1962, 1971, 2002 e 2013. Los resultados apuntan a un cambio notable en la expansión urbana, en la salud pública y la modificación de los cultivos agrícolas. Un trabajo de este tipo asume nivel significativo, por lo que ofrece una base de datos para posibles mejoras relacionadas con las cuencas hidrográficas enfocado.
\end{abstract}

PALABRAS CLAVE: Cuenca Hidrográfica, Geoprocesamiento, Calidad Del Medio Ambiente

\section{INTRODUÇÃO}

Em pleno século XXI os problemas que se manifestam no meio urbano e rural resultante do crescimento mal planejado das cidades brasileiras e de um inadequado manejo agrícola, estão originando nas últimas décadas, mesmo que de maneira tímida, uma demanda de estudos técnicos no âmbito das bacias hidrográficas.

A necessidade de planejar o estudo referente à bacia hidrográfica se arremete como passo fundamental entre as pesquisas sobre as temáticas dos recursos hídricos, ou seja, conseguir abordar as variáveis demográficas, ambientais, culturais, gestão, atividades econômicas da região.

Considerou de forma fundamental aproveitar os aspectos naturais, ou seja, o alto curso da bacia hidrográfica do córrego do Rancho, que abrange as micro-bacias dos córregos Taipus, Tocantins e Rancho para realizar estudos referentes ao uso e ocupação do solo, utilizando técnicas de Geoprocessamento, e ao mesmo tempo, desenvolver habilidades para estas novas tecnologias amplamente utilizadas nas mais diversas áreas de Engenharias. Com o intuito de diagnosticar a qualidade ambiental da Bacia Hidrográfica em foco, ou seja, de maneira que [...] "realize um zoneamento ambiental com base em múltiplas características ambientais, estas naturalmente convergentes em cada local para a definição da situação ambiental em 
análise sendo executadas por Sistema de Informação Geográfica (SIGs)" (GUERRA; CUNHA 2007).

Em panorama com a problemática ambiental e social que envolve o tema, se justifica a importância de trabalhos sobre o levantamento da qualidade ambiental que analisem com seriedade os problemas que se manifestam em Adamantina-SP, e, paralelamente, as realizações destes estudos sirvam para assimilar novas tecnologias e buscar soluções aos problemas socioambientais.

Pelo caráter integrador, a bacia hidrográfica pode ser considerada como excelente unidade de gestão dos elementos naturais e sociais.(GARCEZ; ALVAREZ, 1988).

Os resultados apontam por mudanças notáveis no território da bacia hidrográfica em foco, de tal modo, a expansão urbana, alguns aspectos relacionados à saúde pública e as mudanças de culturas desencadearam os fatores de total observância ao longo deste mapeamento. A busca pela preservação da água e preocupação da mesma se evidencia atualmente, no qual, este estudo está amparado por monitoramentos que levem à compreensão de uma natureza integrada se caracterizando por uma iniciativa que atende a uma demanda socioambiental.

\section{OBJETIVO GERAL}

Utilizar técnicas de Geoprocessamento para caracterizar a ocupação e o uso do solo na bacia hidrográfica do córrego do rancho em Adamantina - SP, refletindo sua qualidade ambiental, elaborando mapas temáticos para identificar as mudanças no período descrito para gerar uma base de dados que sirva de planejamento inicial para futuros estudos e aprofundamentos do tema.

\section{METODOLOGIA}

\section{Aspectos hidrográficos de Adamantina}


O Estado de São Paulo está dividido em 22 Unidades Hidrográficas de Gerenciamento de Recursos Hídricos (UGRHI). Adamantina está inserida nas seguintes Unidades de Gerenciamento: (UGRHI 20 - Aguapeí e UGRHI 21 - Peixe). À Sudoeste, os rios pertencem à Bacia Hidrográfica do Peixe, e a Noroeste pertencem à Bacia Hidrográfica do Aguapeí. Sendo assim, a divisão ficou composta em seis sub-bacias para elaboração do Plano de macrodrenagem do município. Essas sub-bacias são compostas por drenagens de pequeno porte, no qual, 03 subbacias fazem parte da Bacia Hidrográfica do Aguapeí: (Córrego da Esperança, Córrego do Oriente e Córrego Lambari) e 03 sub-bacias compõem a Bacia Hidrográfica do Peixe (Córrego Taipus, Córrego Tocantins e Ribeirão dos Ranchos) vide figura 01.

Figura 01: Mapa da rede hidrográfica do município de Adamantina - SP Fonte: IPT

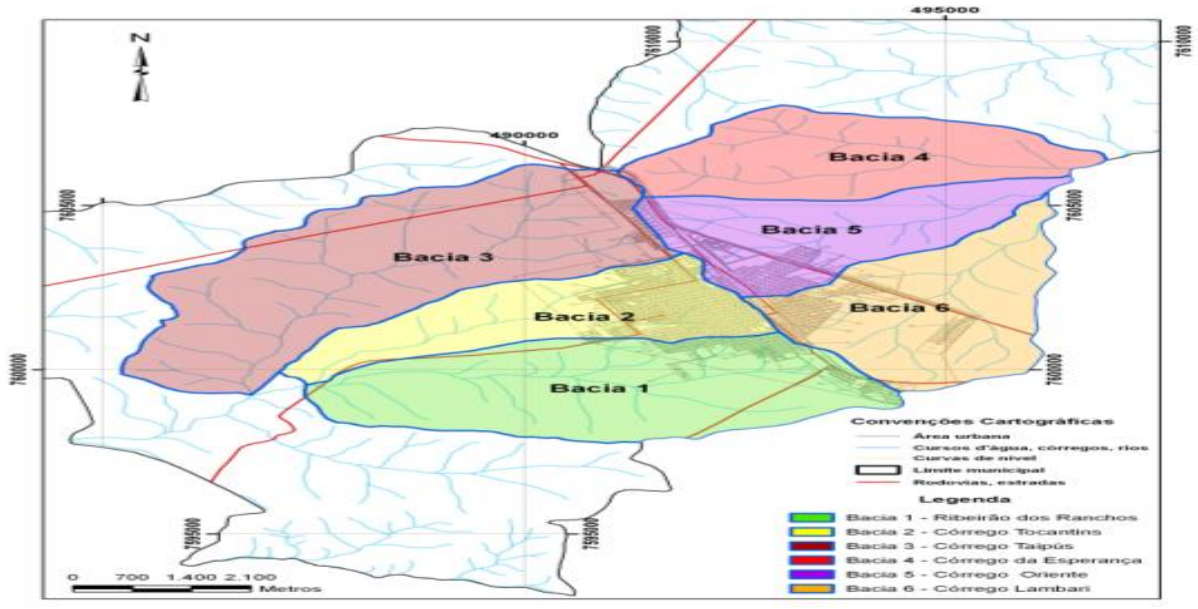

\section{Imagens utilizadas}

O acervo do projeto ficou composto por duas fotos aéreas dos anos de 1962 e 1971 disponibilizadas pela Coordenadoria de Assistência Técnica Integral - CATI com sede no município de Adamantina vide figuras 02 e 03, uma imagem do satélite Landsat 07 datada de 09/04/2002 órbita 222, ponto 075, tempo central de 13:11:19 disponibilizada gratuitamente pelo Instituto Nacional de Pesquisas Espaciais INPE, vide figura 04 e por final uma imagem do satélite Landsat 08 datada de 09/11/2013, órbita 222, ponto 075, tempo central 13:23:58 disponibilizada gratuitamente através de download pelo site do Governo dos Estados Unidos da América USGS - Science for a changing world vide figura 05. 
Figura 02: Aerofoto de 1962.

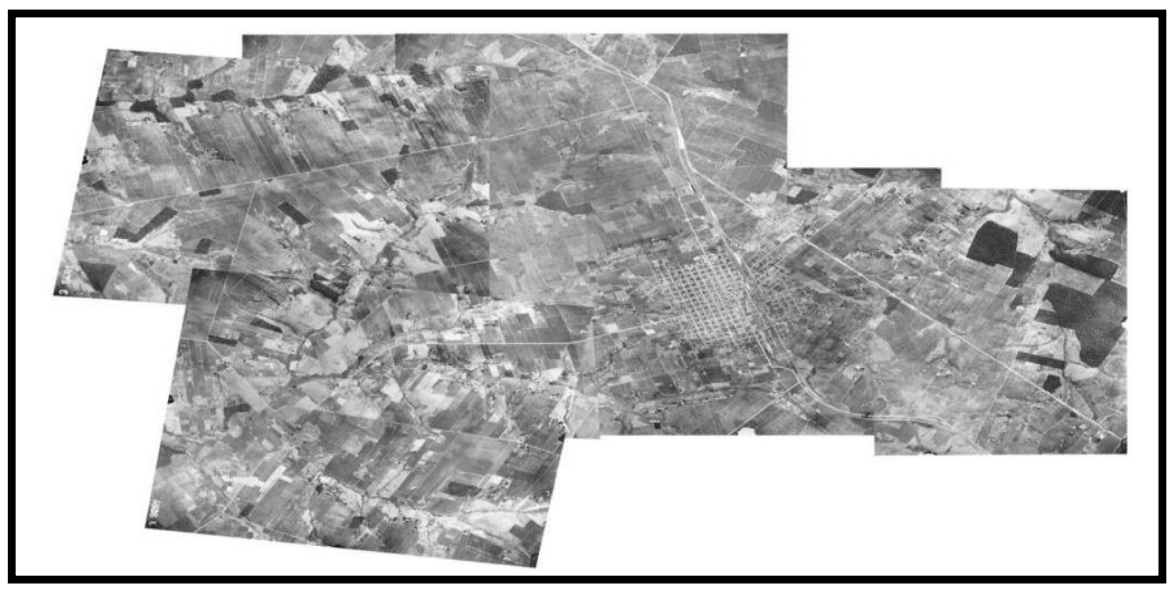

Fonte: CATI

Figura 03: Aerofoto de 1971

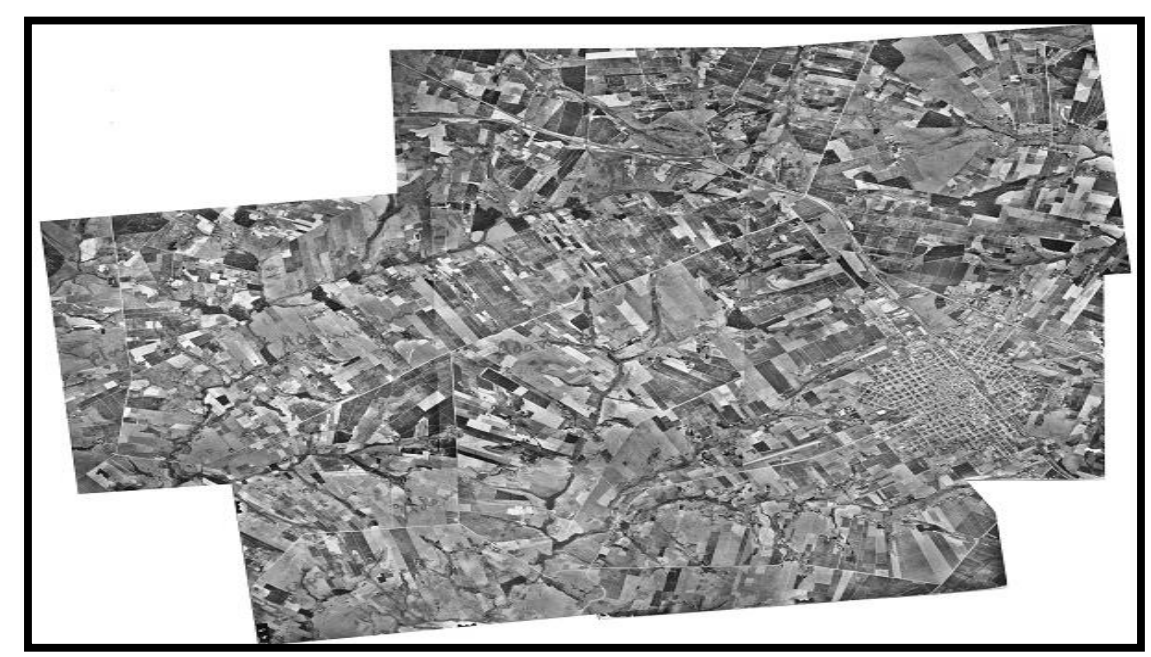

Fonte: CATI 
Figura 04: Imagem de Satélite Landsat 7, 2002 INPE

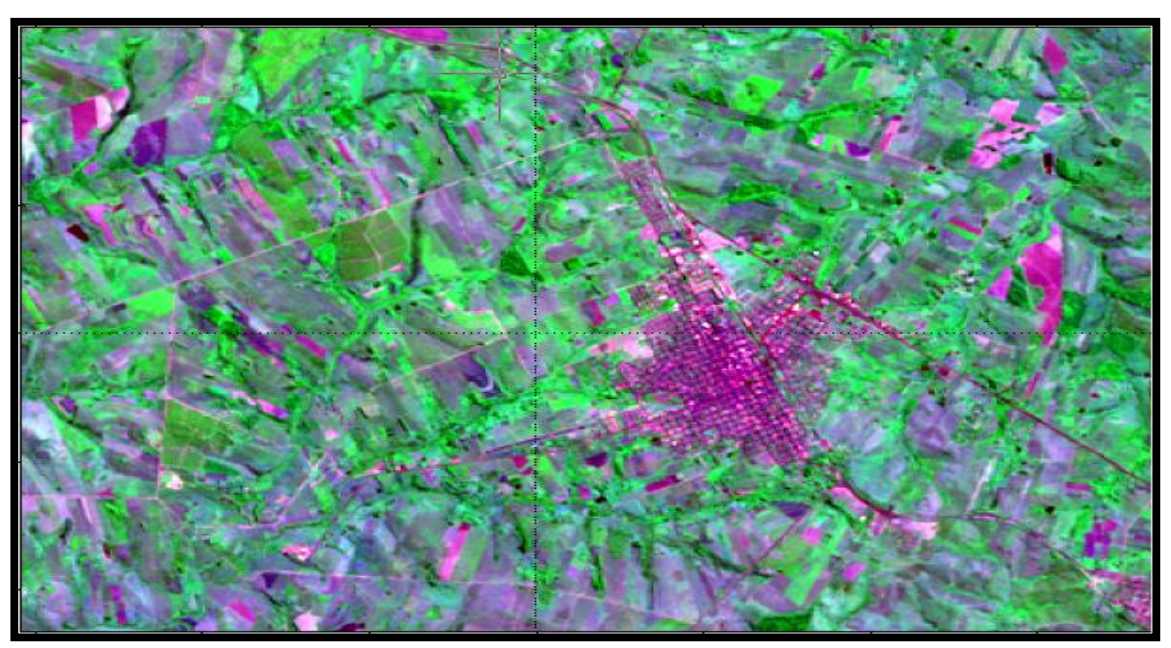

Figura 05: Imagem de Satélite Landsat 8, 2013. Fonte: USGS

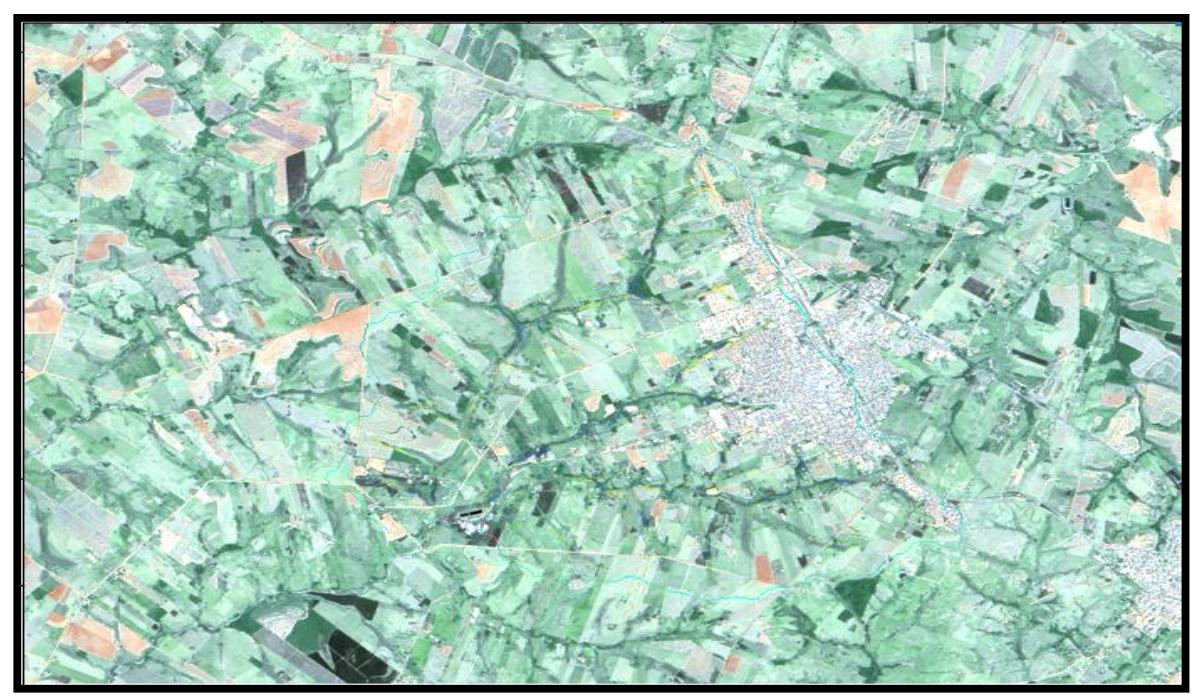

\section{Sistemas utilizados}

Os softwares aptos e utilizados nesta pesquisa foram: AUTO CAD (disponível pela AUTODESK através de licença usual pela instituição responsável); SPRING (disponível gratuitamente para download pelo Instituto Nacional de Pesquisas Espaciais - INPE) e GOOGLE EARTH (disponível gratuitamente para download através do site do Google). O SPRING foi utilizado como ferramenta alternativa, na busca de uma metodologia simplificada. Já o GOOGLE EARTH foi utilizado como uma matriz básica de interpretação, devido ao fato de uma alta resolução encontrada em seu acervo. 
As informações extraídas, bem como os mapas temáticos sobre o uso e ocupação do solo foram elaboradas pelo software AUTO CAD. A dificuldade enfrentada em avaliar as aerofotos de 1962 e 1971, foram devido à resolução evidenciada naquela época, a técnica em questão se baseou em averiguar os aspectos que a imagem oferecia e o levantamento histórico da região. Para confirmar as hipóteses em termos de Geociências e na proposta em questão, como já é uma técnica apropriada o levantamento de campo paralelo à interpretação de imagens de satélites, associou-se esta prática em questão para o aproveitamento máximo de informação e demais características do local.

\section{RESULTADOS}

A imagem aérea de 1962 aponta naquela época como cultura aplicada o Café, ocupando cerca de $50 \%$ da área, ou seja, a economia do município se baseava neste cultivo agrícola. Bem como, se evidencia um alto desmatamento, restando apenas $3,5 \%$ de Vegetação. Ao longo dos cursos d'água se formaram áreas desmatadas, crescendo então as porcentagens de Pastagem 38\%. As Culturas Temporárias citadas como: (algodão, milho) representavam certa significativa chegando aproximadamente a 3,7\%. Estes dados se ilustram melhor logo abaixo como tabela 01 e figura 06.

Tabela 01: Delimitação Imagem - 1962: Uso e Ocupação do Solo Ao Longo Da Bacia

\begin{tabular}{|l|c|c|c|}
\hline \multicolumn{4}{|c|}{ DELIMITAÇÃO IMAGEM 1962} \\
\hline $\begin{array}{c}\text { USO E OCUPAÇÃO DO SOLO AO } \\
\text { LONGO DA BACIA }\end{array}$ & Área em $\mathbf{~ m}^{2}$ & Porcentagens & $\begin{array}{c}\text { Área em } \\
\text { Hectares }\end{array}$ \\
\hline CULTURA PERMANENTE (CAFÉ) & $23.746 .596,16$ & $48,42 \%$ & $2.374,66$ \\
\hline CULTURA TEMPORÁRIA & $1.823 .808,65$ & $3,72 \%$ & 182,38 \\
\hline MATA NATIVA & $1.757 .812,85$ & $3,58 \%$ & 175,78 \\
\hline PASTAGEM & $18.892 .931,35$ & $38,53 \%$ & $1.889,29$ \\
\hline URBANIZAÇÃO & $2.818 .473,42$ & $5,75 \%$ & 281,85 \\
\hline LIMITE DE BACIA (área total) & $49.039 .622,43$ & $100 \%$ & $4.903,96$ \\
\hline
\end{tabular}

. Fonte: Arquivo Pessoal 
Figura 06: Mapa llustrativo - Aerofoto - 1962 - AUTOCAD.

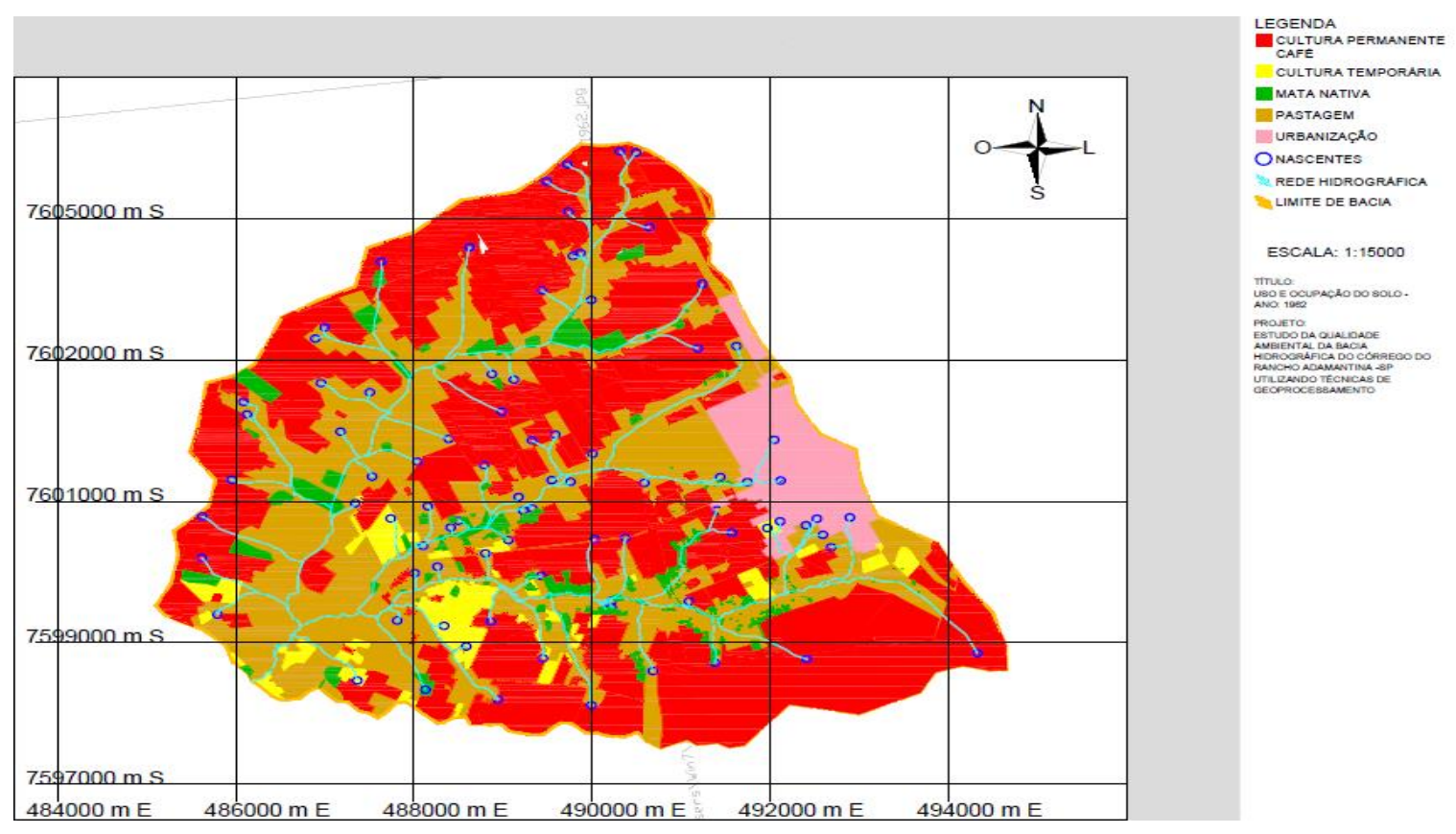

Fonte: Arquivo Pessoal

Comparando com a imagem de 1971 aproximadamente 10 anos após, o Café que representava cultura econômica da região passou de 50\% para 30\%. Frente a este panorama, as porcentagens de pastagem tenderam a aumentar. Logo, a ocupação urbana em torno da Bacia saltou de aproximadamente 5,7 \% para 7,8\%. Para esta data, o município de Adamantina - SP captava água por meio de um reservatório que foi construído no córrego Taipus, com o passar do tempo o município optou por outras medidas de abastecimento público, sendo assim, este reservatório extinto a partir dos anos seguintes. Estas informações se ilustram melhor logo abaixo como tabela 02 e figura (07).

Tabela 02: Delimitação Imagem - 1971: Uso e Ocupação do Solo Ao Longo Da Bacia DELIMITAÇÃO IMAGEM - 1971

\begin{tabular}{|c|c|c|c|}
\hline $\begin{array}{c}\text { USO E OCUPAÇÃO DO SOLO AO } \\
\text { LONGO DA BACIA }\end{array}$ & Área em m $^{2}$ & Porcentagens & $\begin{array}{c}\text { Área em } \\
\text { Hectares }\end{array}$ \\
\hline CULTURA PERMANENTE (CAFÉ) & $14.748 .013,88$ & $30,07 \%$ & $1.474,80$ \\
\hline CULTURA TEMPORÁRIA & $557.778,65$ & $1,14 \%$ & 55,78 \\
\hline MASSA HÍDRICA (RESERVATÓRIO) & $69.345,61$ & $0,14 \%$ & 6,93 \\
\hline MATA NATIVA & $1.955 .566,06$ & $3,99 \%$ & 195,56 \\
\hline PASTAGEM & $27.854 .121,57$ & $56,80 \%$ & $2.785,41$ \\
\hline URBANIZAÇÃO & $3.854 .796,66$ & $7,86 \%$ & 385,48 \\
\hline LIMITE DE BACIA (área total) & $49.039 .622,43$ & $100,00 \%$ & $4.903,96$ \\
\hline
\end{tabular}


Figura 07:Mapa llustrativo - Aerofoto - 1971- AUTOCAD.
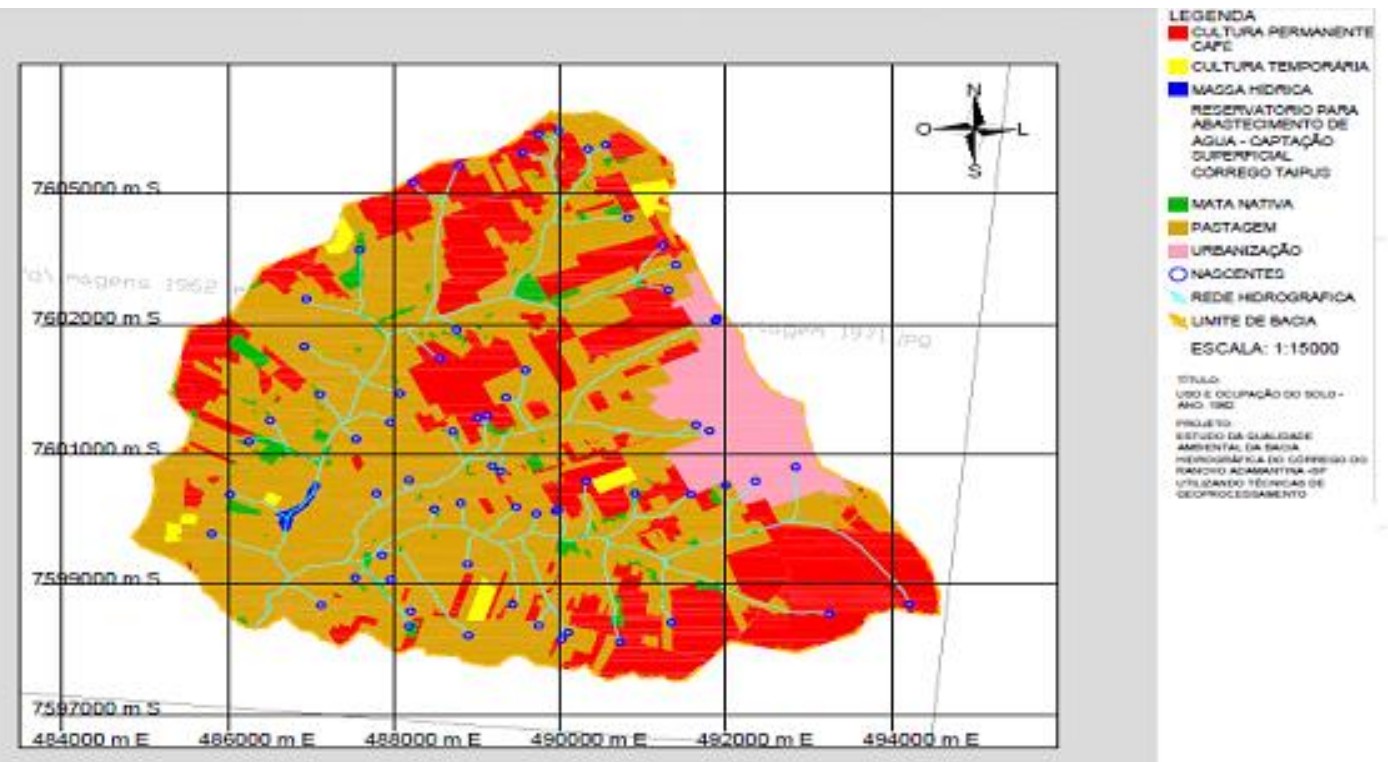

Fonte:

Arquivo Pessoal

Cerca de 30 anos após, o cenário do município de Adamantina muda completamente. No ano de 2002 já se verifica instalações da empresa de Curtição de Couro - (Adacouro) ocupando uma área de 07 Hectares representando 0,14\% da ocupação da Bacia. Logo, nesta imagem constata-se a instalação do Aeroporto, ocupando 11,25 hectares representando $0,23 \%$ da ocupação territorial. Um fator preocupante é a alta concentração de lixo em céu aberto, este Aterro representa nesta data 4,5 hectares, ocupando $0,09 \%$ da área territorial da bacia. A partir da década de 2000 o Café deixou de assumir a importância econômica, uma cultura que representava $50 \%$ do território da Bacia, já nesta época se estagnou representando apenas $2,53 \%$ de área cultivada. A Cana de Açúcar, cultura recentemente implantada apresentou 922,75 hectares representando $18,82 \%$ do território da Bacia. Em análise, as Culturas Temporárias se concentram em pequenas propriedades, assumem áreas pouco significativas. Um dado importante foi o aumento da vegetação comparado com os números anteriores, passando de aproximadamente $3,5 \%$ para $7,4 \%$ totalizando uma área de 366,61 hectares. Logo, a expansão urbana tendeu a aumentar, passando de 7,8\% para $12,13 \%$ representando 595,06 hectares de construção. A silvicultura (cultivo de seringueira, eucalipto dentre outros) começou a surgir no município, levando o produtor a investir 
nesta modalidade de cultura. Estas informações se ilustram melhor de acordo com a tabela 03 e figura 08.

Tabela 03: Delimitação Imagem - 2002 Uso e Ocupação do Solo Ao Longo da Bacia.

\begin{tabular}{|l|r|r|r|}
\hline \multicolumn{3}{|c|}{ DELIMITAÇÃO IMAGEM - 2002} \\
\hline $\begin{array}{l}\text { USO E OCUPAÇÃO DO SOLO AO } \\
\text { LONGO DA BACIA }\end{array}$ & \multicolumn{1}{|c|}{ Área em m ${ }^{2}$} & Porcentagens & $\begin{array}{c}\text { Área em } \\
\text { Hectares }\end{array}$ \\
\hline $\begin{array}{l}\text { INDÚSTRIA DE CURTIÇÃO DE } \\
\text { COURO }\end{array}$ & $70.237,40$ & $0,14 \%$ & 7,02 \\
\hline AEROPORTO & $112.510,79$ & $0,23 \%$ & 11,25 \\
\hline ATERRO & $45.405,46$ & $0,09 \%$ & 4,54 \\
\hline CANA DE AÇÚCAR & $9.227 .535,00$ & $18,82 \%$ & 922,75 \\
\hline CULTURA PERMANENTE (CAFÉ) & $1.239 .990,47$ & $2,53 \%$ & 124,00 \\
\hline CULTURA TEMPORÁRIA & $821.623,80$ & $1,68 \%$ & 82,16 \\
\hline MATA NATIVA & $3.666 .115,36$ & $7,48 \%$ & 366,61 \\
\hline PASTAGEM & $27.190 .992,42$ & $55,45 \%$ & $2.719,10$ \\
\hline SILVICULTURA & $714.565,50$ & $1,46 \%$ & 71,46 \\
\hline URBANIZAÇÃO & $5.950 .646,25$ & $12,13 \%$ & 595,06 \\
\hline LIMITE DE BACIA (área total) & $49.039 .622,43$ & $100,00 \%$ & $4.903,96$ \\
\hline
\end{tabular}

Fonte: Arquivo Pessoal

Figura 08: Mapa llustrativo -imagem de satélite 2002 - AUTO CAD.

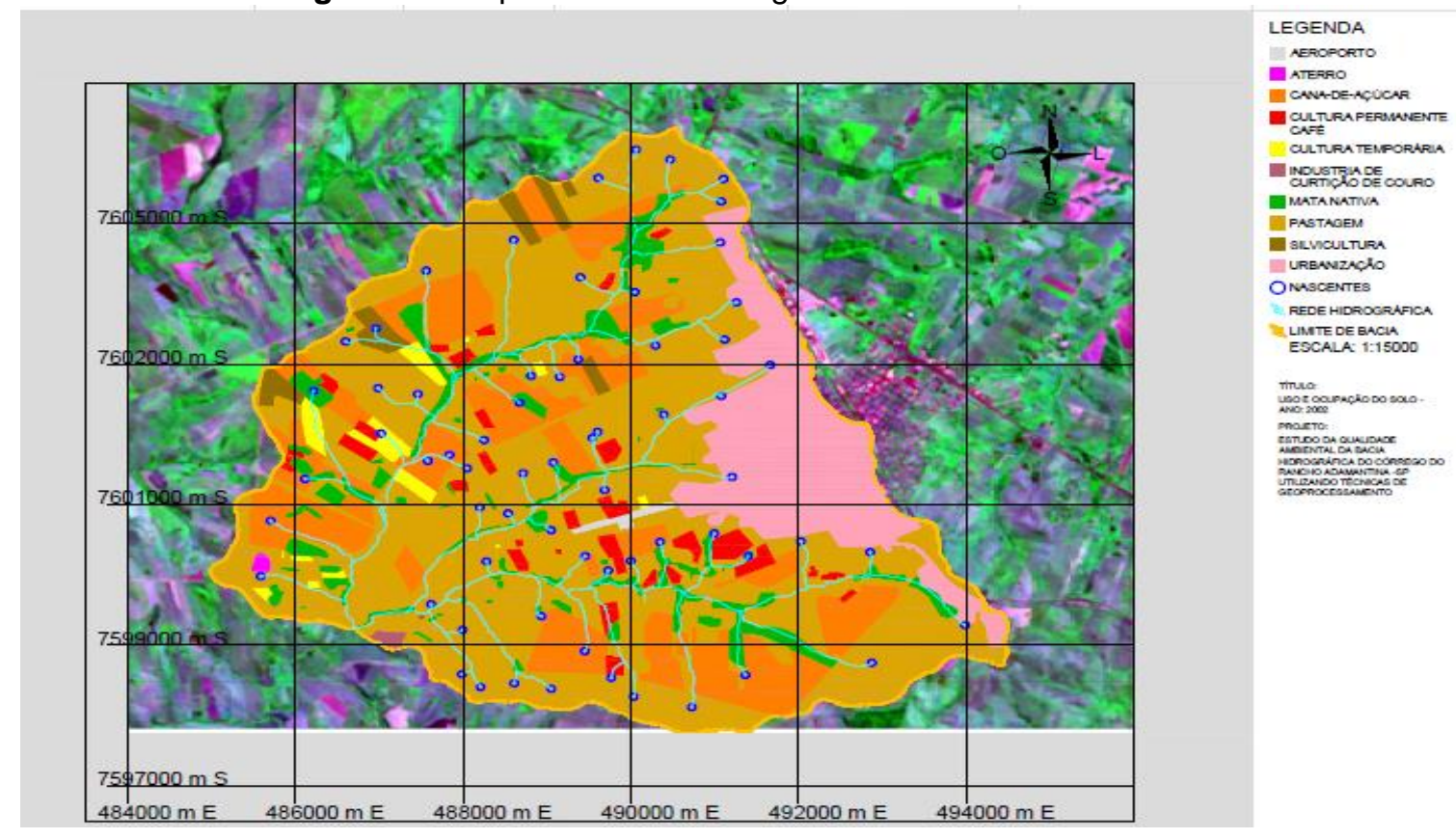

Fonte: Arquivo Pessoal

A imagem de 2013 ressalta dados próximos a realidade. Alguns mantiveram certo equilíbrio em consonância com os anteriores, todavia, algumas mudanças ocorreram. Para o ano de 2002 não se evidenciou nenhuma coleta ou possibilidade 
de tratamento de esgoto para esta área, pois a estação de tratamento de esgoto Oeste foi inaugurada nos anos seguintes, hoje ocupa uma área de 9,32 hectares representando $0,19 \%$ da área territorial, assumindo fundamental importância quando se avalia os critérios ambientais ligados a qualidade de vida da população. Ao todo, $68 \%$ desta bacia em estudo são ocupadas por pastagem, ou seja, a cana de açúcar que apontou valores significativos de crescimento nos dados anteriores acabou perdendo o rendimento. A ocupação urbana passou de 281,85 Hectares para 731 Hectares em 2013 assumindo aproximadamente 15\% do território da Bacia Hidrográfica. As informações se ilustram melhor de acordo com a tabela 04 e figura 09

Tabela 04: Delimitação imagem - 2013. Uso e Ocupação do Solo Ao Longo da Bacia.

\begin{tabular}{|c|c|c|c|}
\hline \multicolumn{4}{|c|}{ DELIMITAÇÃO IMAGEM - 2013} \\
\hline $\begin{array}{c}\text { USO E OCUPAÇÃO DO SOLO AO LONGO } \\
\text { DA BACIA }\end{array}$ & Área em $\mathrm{m}^{2}$ & Porcentagens & $\begin{array}{l}\text { Área em } \\
\text { Hectares }\end{array}$ \\
\hline INDÚSTRIA DE CURTIÇÃO DE COURO & $94.716,35$ & $0,19 \%$ & 9,47 \\
\hline AEROPORTO & $75.687,21$ & $0,15 \%$ & 7,57 \\
\hline ATERRO & $183.843,59$ & $0,37 \%$ & 18,38 \\
\hline CANA DE AÇÚCAR & $1.676 .784,06$ & $3,42 \%$ & 167,68 \\
\hline CULTURA PERMANENTE (CAFÉ) & $39.818,01$ & $0,08 \%$ & 3,98 \\
\hline CULTURA TEMPORÁRIA & $1.464 .948,91$ & $2,99 \%$ & 146,49 \\
\hline ESTAÇÃO DE TRATAMENTO DE ESGOTO & $93.194,61$ & $0,19 \%$ & 9,32 \\
\hline MATA NATIVA & $3.357 .455,59$ & $6,85 \%$ & 335,75 \\
\hline PASTAGEM & $33.729 .727,05$ & $68,78 \%$ & $3.372,97$ \\
\hline SILVICULTURA & $1.013 .261,65$ & $2,07 \%$ & 101,33 \\
\hline URBANIZAÇÃO & $7.310 .185,41$ & $14,91 \%$ & 731,02 \\
\hline LIMITE DE BACIA (área total) & $49.039 .622,43$ & $100,00 \%$ & $4.903,96$ \\
\hline
\end{tabular}

Fonte: Arquivo Pessoal. 
Figura 09: Mapa llustrativo - imagem de satélite - 2013 - AUTO CAD

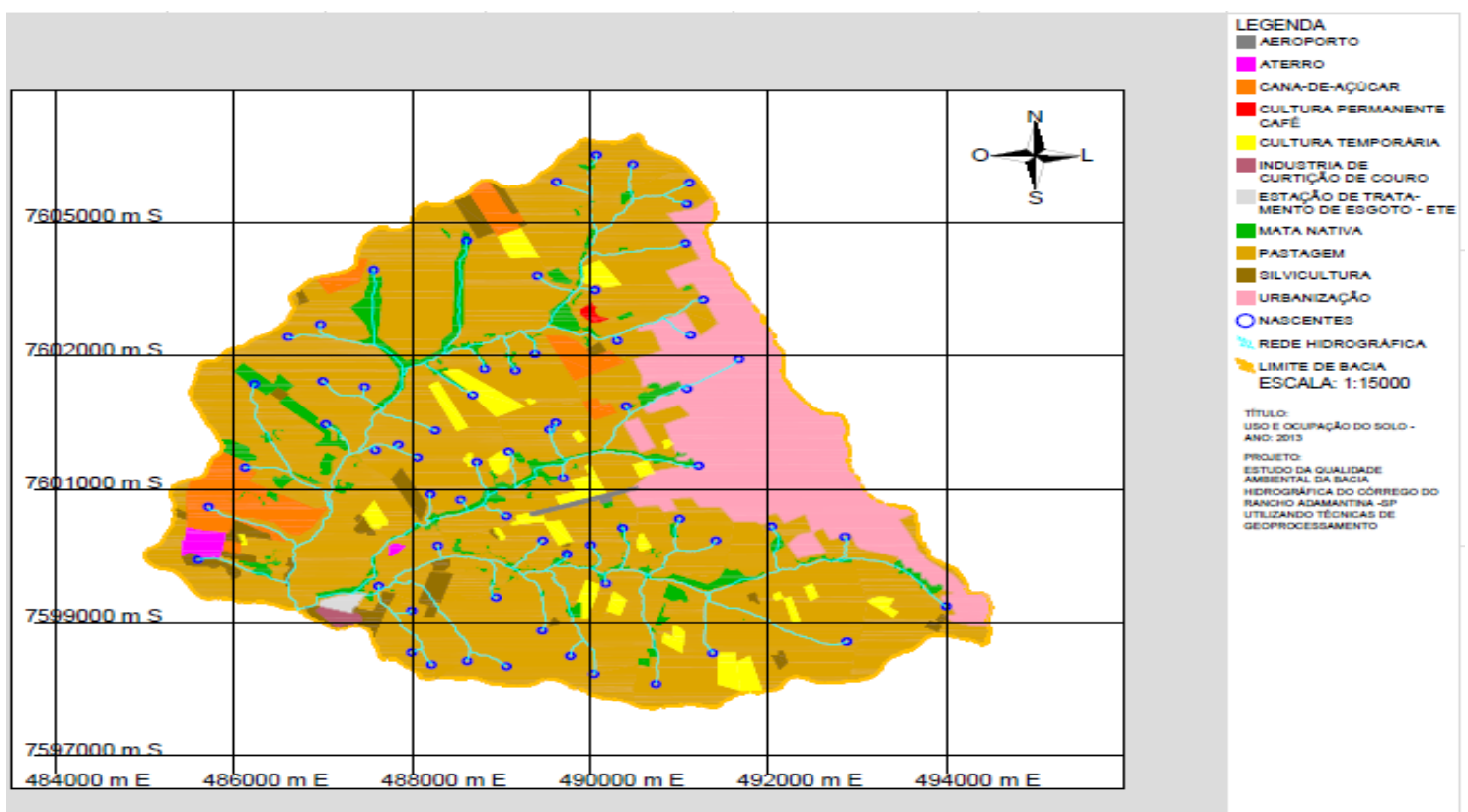

. Fonte: Arquivo Pessoal

Para maior ilustração das informações contidas nas tabelas e descritas no texto, segue logo abaixo como gráfico 01 a variação obtida ao longo do processamento das imagens contidas neste trabalho.

Gráfico 01: Comportamento da Ocupação em Hectares.

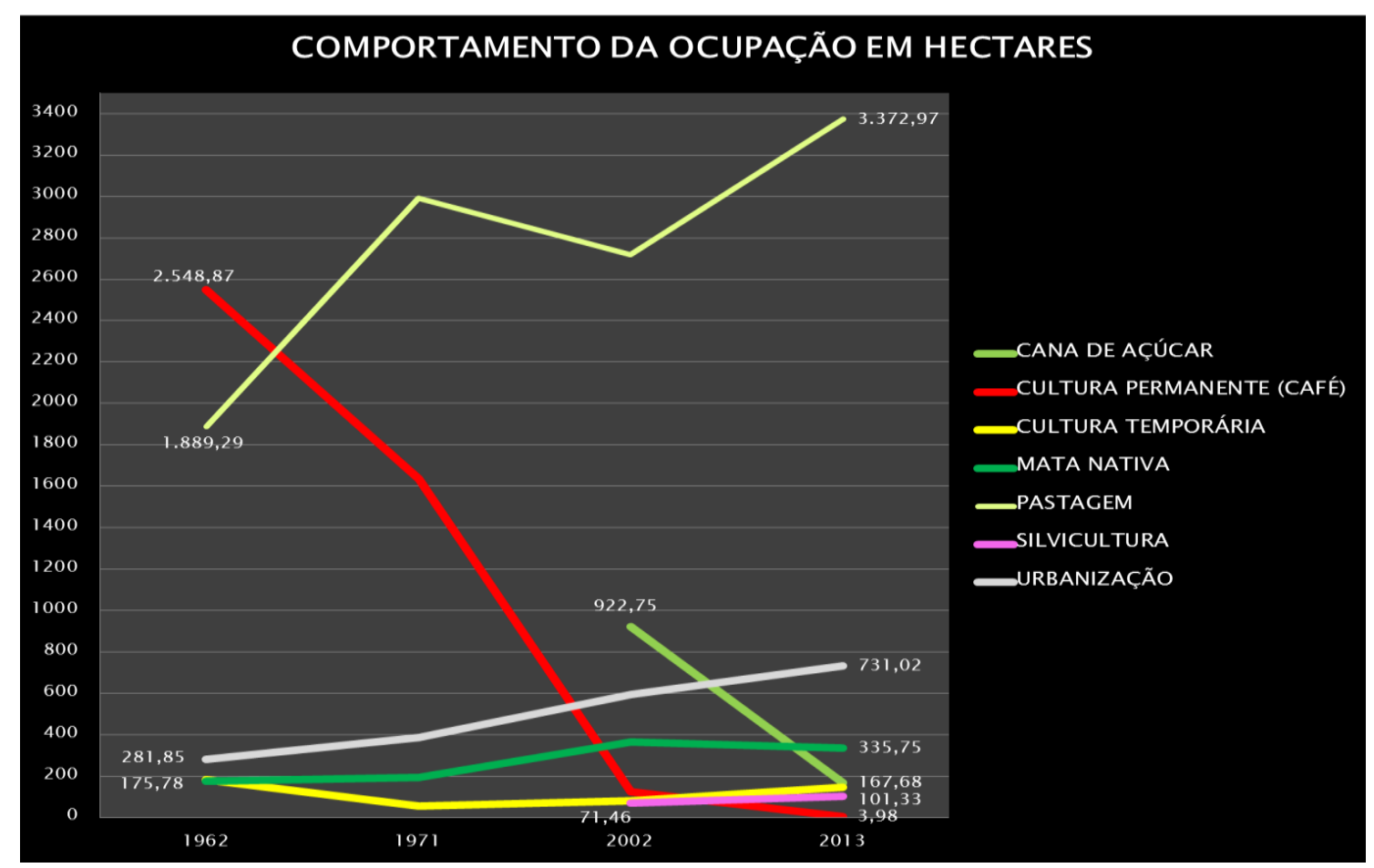




\section{CONCLUSÃO}

O homem sempre interagiu e utilizou o meio ambiente, construiu habitações, desenvolveu suas demais técnicas de sobrevivência e avançou tecnologicamente. Preocupações referentes aos recursos naturais e preservação dos mesmos se evidenciam nos dias atuais, enfrentamos uma ocupação urbana crescente e desordenada, e manter a qualidade de vida nos próximos anos faz refletir e agir. Nota-se que ao longo dos anos os proprietários optaram por outras modalidades de cultura, juntamente com a expansão do município vários aspectos surgiram como: o acúmulo de lixo, construção de aeroporto, novas empresas, estação de tratamento de esgoto e reflorestamento de mata ciliar.

\section{REFERÊNCIAS}

ALMEIDA, J.R; AMARAL, C.P; CUNHA, S.B; FERNANDES, N.F; GUERRA, A.J.T; LARACH, J.O.I; PALMIERI, $\mathrm{F}$; PEREIRA, J.B.S; PORTO, C.G; ROSS, J.L.S; SUERTEGARAY, D.M.A. Geomorfologia e Meio Ambiente. 6ed. Rio de janeiro. Bertrand Brasil, 2006.

GARCEZ, L.N; ALVAREZ, G. A. Hidrologia. 2ed atualizada. São Paulo. Editora Edgard Blucker, 1988

GUERRA, A. J. T; CUNHA, S. B. Geomorfologia uma atualização de bases e conceitos. 7ed. Rio de janeiro. Bertrand Brasil, 2007.
GOOGLE.
GOOGLE
EARTH.
Software
disponível
em:

http://www.google.com.br/earth/download/ge/agree.html

INPE. Instituto Nacional de Pesquisas Espaciais. SPRING. Disponível em: http://www.dpi.inpe.br/spring/. Copyright @ 1991-2014.

SÃO PAULO-SP, Parecer técnico número 15713-301-1 - IPT - Instituto de Pesquisas Tecnológicas - Plano de macrodrenagem do município de Adamantina-SP - IPT - 2009.

NOGUEIRA, R. E. Cartografia, representação, comunicação e visualização dos dados espaciais. 2ed. Florianópolis. Editora UFSC, 2008.

USGS.Science for a changing world.Satélite Landsat 08. Disponível em: http://landsat.usgs.gov/. 